\title{
Sex hormones, sexual activity and plasma anticonvulsant levels in male epileptics
}

\author{
BK TOONE, M WHEELER, M NANJEE, P FENWICK, R GRANT \\ From the David Lewis Centre for Epilepsy, Alderley Edge, and the Department of Chemical Pathology, St \\ Thomas's Hospital, London UK
}

SUMmary Testosterone, LH, FSH, PRL, and sex hormone binding globulin (SHBG) were measured in 72 male epileptic patients on chronic anticonvulsant drug regimes. Sexual activity was estimated and plasma anticonvulsants measured. Total testosterone (TT), LH, FSH, PRL, and SHBG were increased; free testosterone (FT) was decreased. Sexual activity appeared diminished particularly in relation to reduced FT.

Disturbances in male sex hormones have been recently reported in male epileptic patients on anticonvulsant drugs. Christiansen et $\mathrm{al}^{1}$ were the first to observe diminished excretion of androsterone and dehydroepiandosterone compared with normal controls. The same group ${ }^{2}$ studied endocrine change after three months of treatment with either phenytoin or carbamazepine. They confirmed the reduced excretion of androgens, but noted an increase in the serum concentration of testosterone in patients on phenytoin. An increase in TT has now been reported by two further groups in association with raised $\mathrm{SHBG}^{34}$. $\mathrm{LH}$ and $\mathrm{FSH}$ were also increased Finally Dana-Haeri et $a^{5}$ have observed reduced levels of FT.

There have been numerous reports of disturbed sexual activity and orientation in epilepsy. Libido may be increased or decreased; sexual orientation may be disturbed, particularly in association with temporal lobe epilepsy. ${ }^{6}$ However, there has been little attempt to explore the relationship between sexual activity and sex hormone function. In order to do this we have investigated the residential population at the David Lewis Centre for Epilepsy. This paper reports changes in sex hormone patterns, relates these to sexual activity and dosage of anticonvulsant drugs.

\section{Patients}

All male patients at the David Lewis Centre who were between the ages of 17 and 60 years and who were on anticonvulsant medication were considered. Twelve who

Address for reprint requests: Dr BK Toone, Maudsley Hospital, Denmark Hill, London SE5 8A2, UK.

Received 9 October 1982 and in revised form 24 February 1983. Accepted 7 May 1983 were receiving medication known to interfere with endocrine function were omitted, as were two patients with evidence of primary endocrine disorders. Seventy-two patients (mean age 34.5 years) finally entered the study. Only six patients were on a single anticonvulsant drug regime. Forty-eight patients were prescribed phenytoin (mean plasma level $9.1 \mathrm{mg} / \mathrm{l}), 19$ phenobarbitone $(11.2 \mathrm{mg} / \mathrm{l})$, 41 carbamazepine $(4.4 \mathrm{mg} / \mathrm{l}), 32$ sodium valproate $(25.3 \mathrm{mg} / \mathrm{l}), 24$ primidone $(2.4 \mathrm{mg} / \mathrm{l})$ and six ethosuximide. Each patient received an average of $2 \cdot 3$ anticonvulsant drugs. Fifteen patients also received some form of benzodiazepine, principally as night sedation. A diagnosis of primary generalised epilepsy was made in eight cases, secondary generalised epilepsy in 19, temporal lobe epilepsy in 32 , and some other form of focal epilepsy in 12. Ten experienced partial seizures with simple symptomatology, 37 partial seizures with complex symptomatology, 44 secondary generalised seizures, 19 generalised tonic-clonic seizures, and five akinetic seizures. The average age of onset was 5.2 years and the duration of epilepsy $29 \cdot 0$ years.

\section{Controls}

Hormonal data was compared with a control group comprising 82 male volunteers from the staff of St Thomas's Hospital (mean age 38.8 years).

\section{Method}

\section{The interview}

The interview was conducted by a consultant psychiatrist (BKT or PF) and lasted approximately 30 minutes. The first part of the interview was unstructured: the subject was encouraged to describe his sexual interests, attitudes and experiences. The meanings of certain technical terms were explained. Complete confidentiality was assured. The subject was then questioned systematically about certain aspects of bodily function, sexual interest, and activity. These were selected to reflect the influence of androgens on sexual behaviour. The level of sexual interest was partly 
adduced from the frequency of sexual thoughts. The sexual activity was said to occur on those occasions when it culminated in orgasm. The circumstances in which it occurred were not enquired into as the study was not primarily concerned with sexual orientation and did not wish to impose on its subjects more than was necessary. Other questions were concerned with the frequency of nocturnal seminal emissions, penile erections on waking, spontaneous erections during the day, and with complaints of erectile and ejaculatory impotence.

\section{Hormonal investigations}

Peripheral venous blood samples were collected immediately after the interview. LH, FSH, PRL, SHBG, TT, FT, $5 \alpha$-dihydrotestosterone (DHT), and plasma anticonvulsant levels were measured. LH, FSH, and PRL were measured by double-antibody radioimmunoassays using MRC standards $68 / 40,69 / 104$ and $71 / 222$ respectively. $\mathrm{LH}$ and FSH antiserum were kindly supplied by Professor WR Butt, Birmingham, and the PRL antiserum by $D r G$ Groom, Cardiff. TT was measured using a PEG-assisted double antibody radioimmunoassay with our own antiserum. ${ }^{7}$ FT was measured by a modification of a method used by Greenstein et al. ${ }^{8}$ DHT was measured by the method of Puri et al, ${ }^{9}$ and SHBG measured by the method of Rudd et al. ${ }^{10}$ Plasma anticonvulsants were measured by the GLC method using methyl-phenytoin as an internal standard.

\section{Results}

HORMONAL DATA

The mean and standard deviation for the hormonal values and SHBG are shown in table 1 . The values for index and control groups differed significantly on each of the measures. Plasma anticonvulsant levels were correlated with hormonal levels, bearing in mind that the majority of patients were on multiple drug regimes. No significant correlations were found for phenytoin or phenobarbitone. Carbamazepine and PRL levels were positively correlated $(r=0.33$; $\mathrm{p}<0 \cdot 05)$. Sodium valproate was correlated significantly with TT $(\mathrm{r}=0.31 ; \mathrm{p}<0.05)$ and positively with $\mathrm{LH}(\mathrm{r}=0.35 ; \mathrm{p}<0.05)$. drive and activity. The latter appeared diminished
Hormonal values were then related to sexual

overall. Four measures, the frequency of sexual activity culminating in orgasm, of early morning erections and of spontaneous day time erections, and erectile impotence, were chosen as the most reliable and relevant indications of sexual drive. Patients were placed in a low drive (not in the past year or never) or high drive (in excess of this) category for each measure. High and low drive groups were then compared with respect to each of the hormonal variables. FT was reduced in the low drive group on all four measures, significantly so in two (table 2). Other hormonal measures failed to discriminate, but both TT $(t=2.04 ; \mathrm{p}<0.05)$ and PRL $(t=2.02 ; \mathrm{p}<0.05)$ were increased in the high drive group using frequency of sexual activity as the behavioural variable. Plasma anticonvulsant levels were correlated with sexual behaviour measures, but no relationship could be detected.

\section{Discussion}

In an earlier study, ${ }^{4}$ we reported raised TT, SHBG and LH in a group of male epileptic patients attending an out-patient department. Sexual activity also appeared reduced, and taking these findings in conjunction, a diminution in FT was predicted. This has recently been reported ${ }^{5}$ and our present data provide further confirmation. In the earlier report we

Table 2 Serum free testosterone in high and low sexual activity epileptic subjects.

\begin{tabular}{|c|c|c|c|c|c|}
\hline & \multicolumn{2}{|c|}{ High Drive } & \multicolumn{3}{|c|}{ Low Drive } \\
\hline & Mean & $(N)$ & Mean & $(N)$ & $t$ \\
\hline $\begin{array}{l}\text { Sexual activity } \\
\text { culminating in orgasm }\end{array}$ & 411.4 & $(22)$ & $314 \cdot 4$ & (41) & $2 \cdot 61^{*}$ \\
\hline Early morning erection & $367 \cdot 8$ & (43) & $299 \cdot 5$ & $(22)$ & $2 \cdot 13^{*}$ \\
\hline $\begin{array}{l}\text { Difficulty in obtaining } \\
\text { an erection }\end{array}$ & $371 \cdot 5$ & (28) & $341 \cdot 3$ & (13) & 0.75 \\
\hline $\begin{array}{l}\text { Frequency of spontaneous } \\
\text { daytime erections }\end{array}$ & $364 \cdot 6$ & (29) & $328 \cdot 6$ & (36) & 1.04 \\
\hline
\end{tabular}

Table 1 Hormonal values: epileptic patients compared with controls

\begin{tabular}{|c|c|c|c|c|c|c|c|}
\hline & \multicolumn{3}{|c|}{ Epileptic patients } & \multicolumn{3}{|c|}{ Control subjects $t^{*}$} & \\
\hline & Mean & $S D$ & $(N)$ & Mean & $S D$ & $(N)$ & \\
\hline $\begin{array}{l}\text { Total testosterone (nmol/l) } \\
\text { Free testosterone (pmol/l) } \\
\text { \% Free testosterone } \\
\text { Dihydrotestosterone (nmol/l) } \\
\text { SHBG }\left(\times 10^{-8} \mathrm{~m}\right)(\mathrm{nmol} / \mathrm{l}) \\
\text { LH (units/1) } \\
\text { FSH (units } / 1) \\
\text { PRL (units } / 1) \text { (milliunits/l) }\end{array}$ & $\begin{array}{c}20.24 \\
345 \cdot 7 \\
1.75 \\
2.87 \\
73.75 \\
8 \cdot 25 \\
4.37 \\
217.6\end{array}$ & $\begin{array}{c}7 \cdot 13 \\
133 \cdot 3 \\
0 \cdot 55 \\
1 \cdot 14 \\
16 \cdot 07 \\
6 \cdot 12 \\
3 \cdot 28 \\
127 \cdot 8\end{array}$ & $\left.\begin{array}{l}72 \\
69 \\
69 \\
72 \\
68 \\
67 \\
68 \\
65)\end{array}\right)$ & $\begin{array}{c}18.03 \\
441 \cdot 1 \\
2.43 \\
1.91 \\
60.45 \\
4.92 \\
2.28 \\
144.5\end{array}$ & $\begin{array}{c}5.99 \\
154.7 \\
0.53 \\
0.65 \\
10.05 \\
2.48 \\
1.36 \\
73.3\end{array}$ & $\begin{array}{l}(82) \\
79 \\
79 \\
82 \\
82 \\
82 \\
82 \\
(82)\end{array}$ & $\begin{array}{l}2.07 \\
4.03 \\
7.61 \\
6.54 \\
6 \cdot 17 \\
4.49 \\
5 \cdot 24 \\
4.35\end{array}$ \\
\hline
\end{tabular}

*Significance of difference: $p<0.001$ in all comparisons. 
were unable to establish an association between hormonal changes and reduced sexual activity; in this study a clear relationship between low drive and FT emerges.

The nature of the study imposed certain methodological constraints. The resident population of the David Lewis Centre is of less than average intelligence and level of educational attainment; they had led relatively sheltered lives. For this reason it was necessary to construct an ad hoc interview schedule rather than use one of the more established methods of enquiry. With respect to the behavioural variables, it was not possible to identify an appropriate control group; such a group should also have been institutionalised, brain-damaged but not epileptic.

There are several possible explanations for the hormonal findings. A fall in plasma testosterone (both free and bound) due to increased metabolism, or, less probably, impaired testicular synthesis leads firstly to a rise in LH with consequent increase in testosterone synthesis and so to an increase in bound testosterone and FT; and secondly to a rise in SHBG, which in turn leads to a further increase in bound testosterone and to a fall in FT. Alternatively, anticonvulsant drugs may induce SHBG directly. A rise in SHBG levels in female patients on phenytoin has been reported, ${ }^{11}$ and its possible use as an index of liver enzyme induction suggested. However, this argument would benefit if sex hormone changes could be related to some index of liver enzyme induction independent of sex hormone metabolism. A drug induced rise in PRL may be the prime mover. An increase in PRL levels leads to a fall in FT and sexual impotence. Both can be reversed by bromocryptine. A final explanation postulates a primary rise in oestrogens leading to an increase in SHBG.

Some other findings require comment. In two earlier studies $^{34}$ TT and SHBG were markedly raised. Dana-Haeri et $a l^{5}$ confirmed the rise in SHBG but not in TT. In the present study, TT and SHBG were raised but less so than previously. ${ }^{6}$ In contrast, the increase in FSH, noted in the original study, was more pronounced. These differences may be related to chronicicity of treatment. The two earlier studies were carried out on outpatient populations; this study and to some extent that by DanaHaeri et al,${ }^{5}$ were based on residential populations in epilepsy centres, with a longer history of exposure to anticonvulsant drugs. Long-term treatment may lead to testicular failure, inability to respond to raised levels of $\mathrm{LH}$, falling testosterone, and eventually, as reported by Christiansen et al, ${ }^{1}$ impaired spermatogenesis. DHT values were found in this study to be higher in the epilepsy than in the control group. This was contrary to expectations and may be explained by the fact that DHT has a greater affinity than FT for SHBG and may consequently be more slowly metabolised.

Christiansen et al ${ }^{1}$ reported an association between impaired potency and reduced urinary excretion of androgens in 98 male epileptics. Our data confirm and extend these findings. We were again unable to establish a clear relationship between plasma levels of individual anticonvulsants and either hormonal or behavioural changes. The exception was sodium valproate, but the pattern of correlations was hard to interpret.

The authors are grateful for the support provided by the Medical Research Council.

\section{References}

' Christiansen P, Deigaard J, Lund M. Potens, Fertilitet of Konshormonudskillelse hos Yngre Manglige Epilepsilidende. Ugeskr Laeger 1975;137:2402-5.

${ }^{2}$ Luhdorf K, Christiansen P, Hansen JM, Lund, N. The influence of phenytoin and carbamazepine on endocrine function: preliminary results. In: Henry JK, ed. Epilepsy, the 8th International Symposium. New York: Raven Press, 1977:209-13.

${ }^{3}$ Barragry JM, Makin HLJ, Trafford DJH, Scott DF. Effect of anticonvulsants on plasma testosterone and sex hormone binding globulin levels. J Neurol Neurosurg Psychiatry 1978;41:913-4.

${ }^{4}$ Toone BK, Wheeler M, Fenwick PBC. Sex hormone changes in male epileptics. Clin Endocrinol 1980;12:391-5.

${ }^{5}$ Dana-Haeri J, Oxley J, Richens E. Reduction of free testosterone by antiepileptic drugs. $\mathrm{Br}$ Med $J$ 1982;284:85-6.

- Toone BK, Wheeler M, Fenwick PBC. Effects of anticonvulsant drugs on male sex hormones and sexual arousal. In: Sandler M, ed. Psychopharmacology of Anticonvulsants. Oxford: Oxford University Press, 1982:136-42.

7 Wheeler MJ, Luther F. Development of testosterone assays for routine use. Hunter WM, Corrie JET, eds. Immunoassays for Clinical Chemistry. Churchill Livingstone 1982. (In press.)

${ }^{8}$ Greenstein BD, Puig-Duran E, Franklin M. Accurate, rapid measurement of the fraction of unbound oestradiol and progesterone in small volumes of undiluted serum at $37^{\circ}$ by miniature steady-state gel filtration. Steroids 1977;30:331-41.

${ }^{9}$ Puri V, Puri CP, Anandkumar TC. Serum levels of dihydrotestosterone in male rhesus monkeys estimated by a non-chromatographic radioimmunoassay method. J Steroid Biochem 1981;14:877-81.

${ }^{10}$ Rudd BT, Duigan NM, London DR. A Rapid Method for the Measurement of Sex-Hormone-BindingGlobulin. Clin Chim Acta 1974;55:165-78.

"Victor A, Lundberg PO, Johansson EDB. Induction of sex-hormone-binding-globulin by phenytoin. $\mathrm{Br}$ Med $J$ 1982;ii:934. 